\title{
Adaptation of a low-cost medium-throughput genotyping system for ovine prion protein gene polymorphims associated with scrapie
}

\author{
P. Ianella ${ }^{1}$, C.M. McManus ${ }^{2,3}$, S.R. Paiva ${ }^{1}$ and A.R. Caetano ${ }^{1}$ \\ ${ }^{1}$ Embrapa Recursos Genéticos e Biotecnologia, Brasília, DF, Brasil \\ ${ }^{2}$ Universidade de Brasília, Brasília, DF, Brasil \\ ${ }^{3}$ Universidade Federal do Rio Grande do Sul, Porto Alegre, RS, Brasil \\ Corresponding author: P. Ianella \\ E-mail: ianellabio@yahoo.com.br
}

Genet. Mol. Res. 10 (4): 3180-3185 (2011)

Received January 6, 2011

Accepted July 20, 2011

Published December 20, 2011

DOI http://dx.doi.org/10.4238/2011.December.20.2

\begin{abstract}
Resistance and susceptibility to scrapie in sheep have been associated with SNPs located at codons 136, 154 and 171 of the prion protein (PRNP) gene. Many countries have sheep breeding programs selecting for resistance to scrapie based on the genotyping of these SNPs. We adapted a fast and robust method for genotyping sheep flocks for these polymorphisms, with reduced costs. Ninety-six samples were genotyped using an adapted SNaPshot PRNP assay, and the results were checked by resequencing. The results showed $100 \%$ concordance, using a method that reduces genotyping costs by $70 \%$, by reducing reagent concentrations in the three main steps of the assay (amplicon purification, base extension and final cleanup). This cost reduction should contribute to the development of selection criteria based on PRNP genotyping in countries where assay costs are an important limiting factor.
\end{abstract}

Key words: PRNP gene; SNaPshot; Sheep 


\section{INTRODUCTION}

Classical scrapie is a fatal and infectious neurodegenerative disease that affects sheep and goats. This disease belongs to the group of transmissible spongiform encephalopathies (TSEs). The prion protein (PRNP) gene encodes the prion protein, which is intrinsically involved in the onset of this disease. Variations in the coding sequence of this gene are strongly associated with susceptibility to the development of TSEs in many mammalian species, including humans (Prusiner and Hsiao, 1994; Mead et al., 2003), cattle (Juling et al., 2006), goats (Vaccari et al., 2009), mice (Carlson et al., 1988), and deer (O'Rourke et al., 1999, 2004). Many polymorphisms in the ovine PRNP have been identified to date, but only the polymorphisms at codons $136(\mathrm{~A} / \mathrm{V}$ - substitution of alanine by valine), $154(\mathrm{R} / \mathrm{H}$ - arginine by hystidine) and $171(\mathrm{Q} / \mathrm{R} / \mathrm{H}$ - glutamine by arginine or hystidine) have been repeatedly associated with the susceptibility of hosts to become naturally and experimentally infected with classical scrapie (Goldmann et al., 1990; Benkel et al., 2007).

The above mentioned PRNP polymorphisms can be found in four main haplotypic variants of the wild-type $A_{136} R_{154} Q_{171}$ (ARQ), with the five most frequently described alleles being: ARQ, ARR, ARH, AHQ, and VRQ (Belt et al., 1995). The ARR allele has been shown to confer resistance to classical scrapie, whereas VRQ is very common in susceptible sheep (Elsen et al., 1999; Goldmman, 2008). The presence of ARR in homozygosis leads to strong, but not absolute, resistance (Groshup et al., 2007). The PRNP genetic association with scrapie resistance/susceptibility is well established and has led to the implementation of large-scale genotyping and selection of breeding stock in several European countries. Many countries have implemented breeding strategies based on PRNP genotyping in order to increase the ARR allele frequency in commercial flocks (Dawson et al., 2008).

Sheep breeding programs in Brazil have yet to incorporate selective breeding strategies based on PRNP genotyping. In addition, only a few studies with small sample numbers, using resequencing or PCR-RFLP strategies, have been recently carried out to evaluate PRNP allele frequencies in a limited number of Brazilian flocks of different breeds (de Lima et al., 2007; Pacheco et al., 2007; Sotomaior et al., 2008; Ianella et al., 2011). Because of the lack of significant information about PRNP allele frequencies in Brazilian flocks, this study aimed to develop reduced-cost adaptations of an existing method to genotype PRNP polymorphisms related to resistance to classical scrapie that could be used as a simple, inexpensive, mediumthroughput assay. Results are reported for the validation of several modifications of a standard protocol for PRNP genotyping that could be useful for routine testing of Brazilian sheep in relation to genetic potential for scrapie susceptibility/resistance.

\section{MATERIAL AND METHODS}

\section{Samples}

Ninety-six DNA samples from 13 different breeds commonly raised in Brazil were used to adapt and validate an assay based on the method developed by Vaccari et al. (2004). Samples from the following sheep breeds were used: locally adapted breeds - Brazilian Bergamasca, Brazilian Creole, Morada Nova, Rabo Largo, Creole of Pantanal, Santa Inês, and Brazilian Somali; commercial/specialized breeds - Corridale, Dâmara, Dorper, Hampshire, Ile de France, and Suffolk. 


\section{PCR amplification}

A 326-bp fragment of the PRNP coding region from selected samples was amplified by PCR using the following primers: 5'-GGTAGCCACAGTCAGTGG-3' and 5'-CAGTTTCGGTGAAGTTCTCC-3' (Vaccari et al., 2004). PCR was carried out in a final volume of $10 \mu \mathrm{L}$ containing $5 \mathrm{ng}$ genomic DNA, $10 \mathrm{mM}$ Tris- $\mathrm{HCl}, \mathrm{pH} 8.3,50 \mathrm{mM} \mathrm{KCl}, 1.25 \mathrm{mM} \mathrm{MgCl}_{2}$, $200 \mathrm{mM}$ dNTPs, $0.125 \mu \mathrm{M}$ of each primer and $0.5 \mathrm{U}$ Taq DNA polymerase. Two microliters of PCR product was purified with an EXOSAP-IT ${ }^{\mathrm{TM}}$ (Amersham) mix $(0.2 \mu \mathrm{L}$ EXOSAP-IT and 1.8 $\mu \mathrm{L}$ water per sample) with the following digestion procedure: $37^{\circ} \mathrm{C}$ for $45 \mathrm{~min}$ and $80^{\circ} \mathrm{C}$ for $15 \mathrm{~min}$.

\section{SNP interrogation assay}

Purified amplicons were submitted to SNaPshot ${ }^{\mathrm{TM}}$ (Applied Biosystems) genotyping reactions with the following previously described oligos (Vaccari et al., 2004): codon 136/ p407 - 5'-TTT TTT TTT TTT TTT GGT GGC TAC ATG CTG GGA AGT G-3', codon 154/ p461: 5'-TTT TTT TTT GGG GTA ACG GTA CAT GTT TTC A-3', and codon 174/p512 5'-CAA GTG TAC TAC AGA CCA GTG GAT C-3' and p513 - 5'-TTT TTT TTT TTT TTT TTT TGC ACA AAG TTG TTC TGG TTA CTA TA-3'. The effects of using different volumes of SNaPshot Multiplex Mix ${ }^{\mathrm{TM}}$ (Applied Biosystems) and shrimp alkaline phosphatase (SAP) were tested, resulting in the following protocol. Reactions were performed in a $10-\mu \mathrm{L}$ final volume, using $0.3 \mu \mathrm{L}$ SNaPshot Multiplex Mix ${ }^{\mathrm{TM}}$ (Applied Biosystems), $2 \mu \mathrm{L}$ purified PCR product and primers p407, p461, p512, and p513 at 0.65, 0.94, 0.095, and $0.94 \mathrm{pmol}$, respectively. Non-incorporated nucleotides were removed by treatment with $2 \mu \mathrm{L}$ SAP (Amersham) mix ( $0.3 \mathrm{U}$ SAP and $1.7 \mu \mathrm{L}$ water). Following these procedures, $1.5 \mu \mathrm{L}$ purified products were

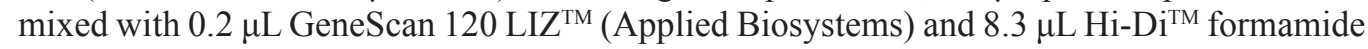
and submitted to capillary electrophoresis in an ABI3100 automated sequencer.

\section{Data analysis}

The electropherograms obtained were analyzed with the GeneMapper ${ }^{\mathrm{TM}}$ software (Applied Biosystems) to genotype each SNP in the samples, and allele frequencies were determined with the Arlequin ver. 3.1 software (Excoffier et al., 2005).

\section{Validation by resequencing}

Genotyping results were cross-validated by resequencing of all samples. Sequencing reactions were carried out with $10 \mathrm{ng}$ of EXOSAPIT-purified DNA following BigDye terminator v. 3 (Applied Biosystems) manufacturer instructions. Electrophoresis was performed in an ABI3100 automated sequencer (Applied Biosystems).

\section{Sequence analysis}

The sequences obtained were analyzed and aligned using the Phred/PhraP/Consed software (Ewing and Green, 1998; Ewing et al., 1998) and SNP genotyping was performed using Polyphred (Nickerson et al., 1997). 


\section{RESULTS AND DISCUSSION}

The protocol modifications tested focused on assay cost reduction without loss of accuracy. Figure 1 shows the results obtained with the use of different concentrations of SNaPshot Multiplex Mix (Applied Biosystems) in the primer extension reactions. With an $88 \%$ reduction in the total volume of SNaPshot Multiplex Mix Reagent used (Figure 1D), in relation to the manufacturer original protocol, it was possible to detect the four investigated SNP peaks and to have an appropriate balance with size-standard peaks. Moreover, the optimal balance between fragment peaks and the GS120LIZ size standard was obtained with only $20 \%$ of the amount recommended by the manufacturer (Figure 1). The modified primer extension protocol resulted in quality genotypes for all 96 samples tested, and all results were confirmed by sequencing.

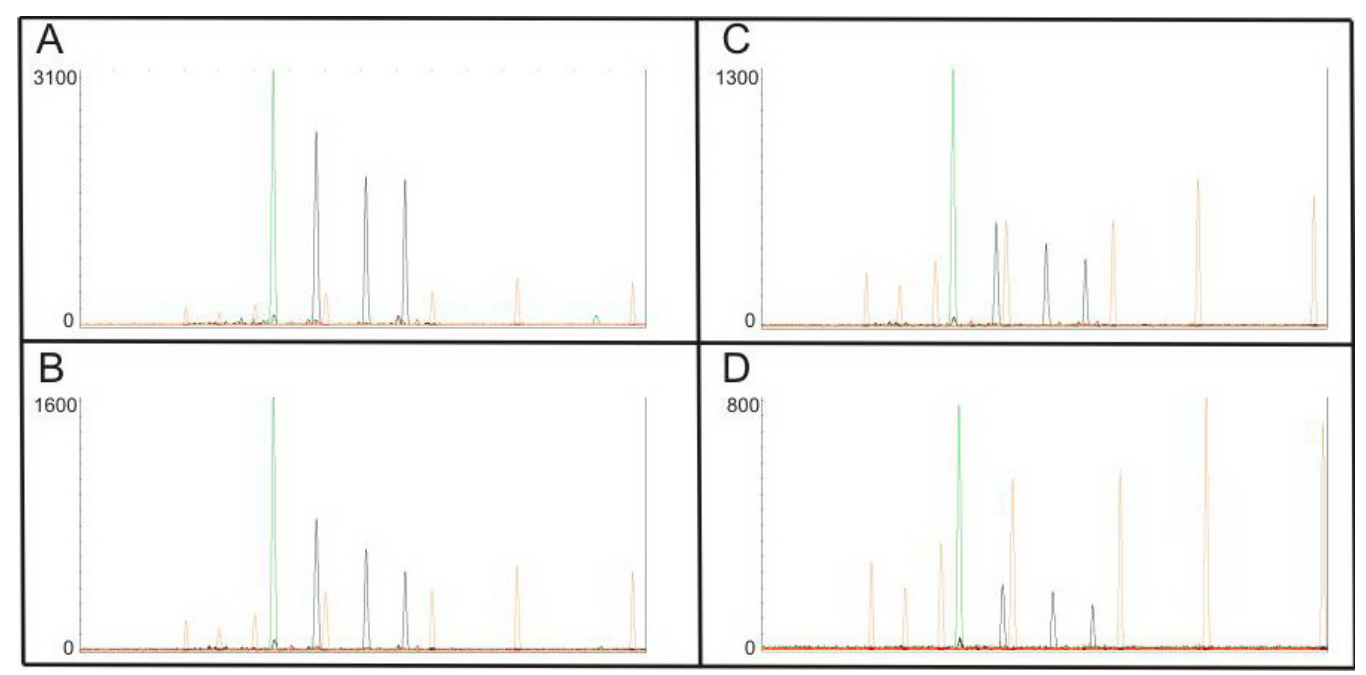

Figure 1. Electropherograms showing SNaPshot reaction products from the different SNPs investigated using different volumes of SNaPshot Multiplex Mix Reagent (Applied Biosystems). A. $2.5 \mu \mathrm{L} ;$ B. $1.0 \mu \mathrm{L} ;$ C. $0.5 \mu \mathrm{L} ; \mathbf{D}$. $0.3 \mu \mathrm{L}$. Orange peaks correspond to the LIZ120 size standard $(0.2 \mu \mathrm{L}$ per sample) left to right: $15,25,35,50,62$, 80, and 110 bp, respectively. Green peak: SNP at the 512 position. Dark peaks (left to right) SNPs at the 461, 407 and 513 positions (according to the reference sequence AJ223072).

The optimized protocol used only $12 \%$ of the SNaPshot Multiplexed Mix suggested by Vaccari et al. (2004) and provided accurate results while significantly reducing assay costs. Other adjustments, such as final reaction volume and concentration of p512 oligonucleotide, were necessary to maintain high quality in the assay. Capillary electrophoresis conditions were also modified in relation to previously published protocols (Vaccari et al., 2004): $1.5 \mu \mathrm{L}(50 \%$ increase) of primer-extension products was used to increase fluorescence signals, and $0.2 \mu \mathrm{L}$ Applied Biosystem's GeneScan LIZ size standard (80\% decrease) was applied in each sample.

Additional modifications were also applied to reduce total assay costs. A $90 \%$ reduction in the total amount of recommended EXOSAP-IT reagent $(0.2 \mu \mathrm{L})$ used for purification of PCR products prior to the primer extension reaction, and a 70\% reduction in the total amount of SAP used to treat primer extension products, consistently produced high-quality results. 
Considering reagent costs, the adaptations tested resulted in a total reduction of $77 \%$ in the primer extension genotyping cost of the four most relevant ovine PRNP polymorphisms.

Figure 2 illustrates an example of genotyped samples carrying polymorphisms at nucleotide positions 461 (codom 154) and 512 (codon 171), according to the reference sequence (AJ223072). Polymorphisms at nucleotide 513 (codon 171 - H variant) were not observed in the samples genotyped. Observed SNP frequencies are listed in Table 1.

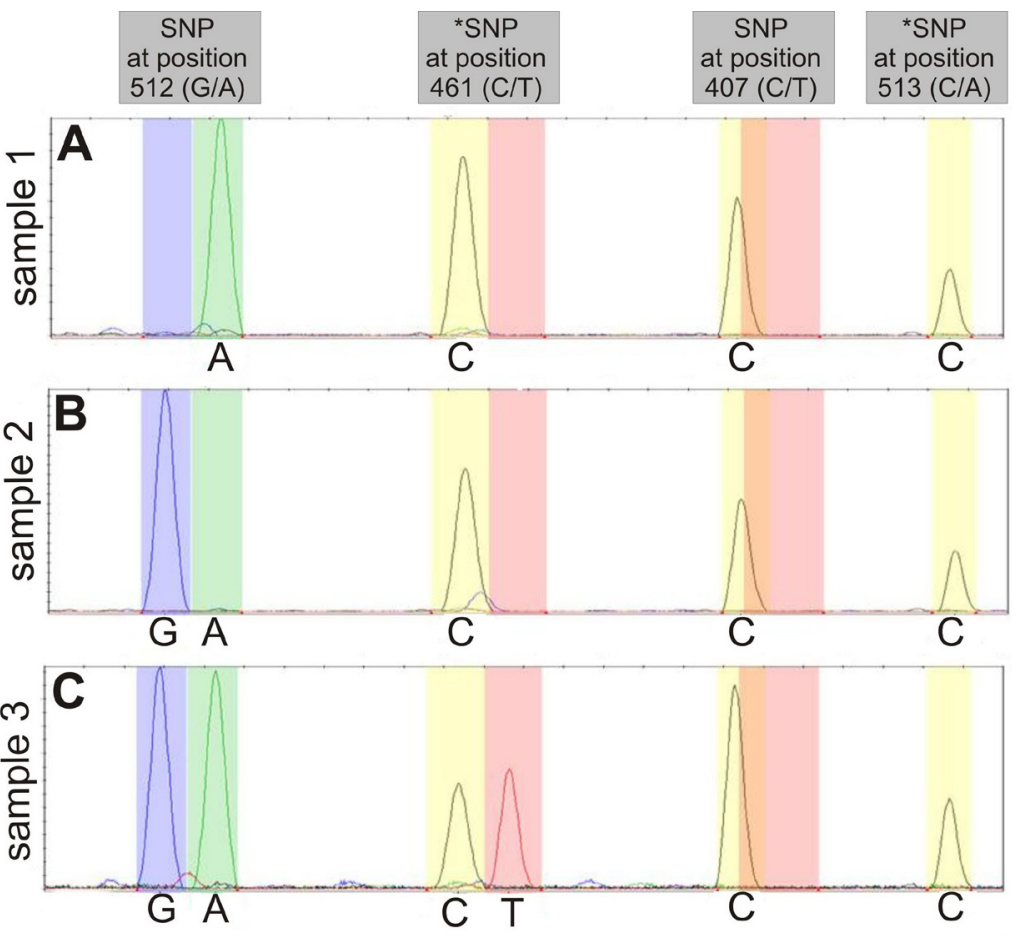

Figure 2. Electropherograms and genotypes generated with the GeneMaper software. A. Sample 1: CC/GG/AA/ GG at the positions 407/461/512/513. B. Sample 2: CC/GG/AG/GG. C. Sample 3: CC/GA/AG/GG. *Nucleotides 461 and 513 were detected by assaying the complementary strain.

Table 1. SNP frequencies at the 407, 461 and 512 positions in the reference sequence (AJ223072) based on the 96 samples tested.

\begin{tabular}{lccc}
\hline SNP position & Codon & Variation & MAF* \\
\hline 407 & 136 & $\mathrm{C}>\mathrm{T}$ & 0.06 \\
461 & 154 & $\mathrm{G}>\mathrm{A}$ & 0.17 \\
512 & 171 & $\mathrm{~A}>\mathrm{G}$ & 0.27 \\
\hline
\end{tabular}

$\mathrm{MAF}=$ minor allelic frequency.

The modified assay shown here was applied to a total of 1400 samples from different breeds/ flocks of sheep sampled in Brazil with a failure rate below 1\% (Ianella et al., 2011), which represents the first comprehensive PRNP genotyping initiative in Brazil. The cost-reductions obtained should contribute to the development of national policies and programs to incorporate animal breeding 
strategies based on PRNP genotyping in countries where assay costs are the main limiting factor.

\title{
ACKNOWLEDGMENTS
}

\author{
Research supported by CNPq (Grant \#300052/2008-1) and Embrapa (Grant \\ \#030801018).
}

\section{REFERENCES}

Belt PB, Muileman IH, Schreuder BE, Bos-de Ruijter J, et al. (1995). Identification of five allelic variants of the sheep $\operatorname{PrP}$ gene and their association with natural scrapie. J. Gen. Virol. 76 ( Pt 3): 509-517.

Benkel BF, Valle E, Bissonnette N and Hossain FA (2007). Simultaneous detection of eight single nucleotide polymorphisms in the ovine prion protein gene. Mol. Cell Probes 21: 363-367.

Carlson GA, Goodman PA, Lovett M, Taylor BA, et al. (1988). Genetics and polymorphism of the mouse prion gene complex: control of scrapie incubation time. Mol. Cell Biol. 8: 5528-5540.

Dawson M, Moore RC and Bishop SC (2008). Progress and limits of PrP gene selection policy. Vet. Res. 39: 25.

de Lima AC, Bossers A, Souza CE, Oliveira SM, et al. (2007). PrP genotypes in a pedigree flock of Santa Ines sheep. Vet. Rec. 160: 336-337.

Elsen JM, Amigues Y, Schelcher F, Ducrocq V, et al. (1999). Genetic susceptibility and transmission factors in scrapie: detailed analysis of an epidemic in a closed flock of Romanov. Arch. Virol. 144: 431-445.

Ewing B and Green P (1998). Base-calling of automated sequencer traces using phred. II. Error probabilities. Genome Res. 8: 186-194.

Ewing B, Hillier L, Wendl MC and Green P (1998). Base-calling of automated sequencer traces using phred. I. Accuracy assessment. Genome Res. 8: 175-185.

Excoffier L, Laval G and Schneider S (2005). Arlequin (version 3.0): an integrated software package for population genetics data analysis. Evol. Bioinform. Online 1: 47-50.

Goldmann W (2008). PrP genetics in ruminant transmissible spongiform encephalopathies. Vet. Res. 39: 30.

Goldmann W, Hunter N, Foster JD, Salbaum JM, et al. (1990). Two alleles of a neural protein gene linked to scrapie in sheep. Proc. Natl. Acad. Sci. U. S. A. 87: 2476-2480.

Groschup MH, Lacroux C, Buschmann A, Luhken G, et al. (2007). Classic scrapie in sheep with the ARR/ARR prion genotype in Germany and France. Emerg. Infect. Dis. 13: 1201-1207.

Ianella P, McManus C, Caetano AR and Paiva SR (2011). PRNP haplotype and genotype frequencies in Brazilian sheep: issues for conservation and breeding programs. Res. Vet. Sci. (in press).

Juling K, Schwarzenbacher H, Williams JL and Fries R (2006). A major genetic component of BSE susceptibility. BMC Biol. 4: 33.

Mead S, Stumpf MP, Whitfield J, Beck JA, et al. (2003). Balancing selection at the prion protein gene consistent with prehistoric kurulike epidemics. Science 300: 640-643.

Nickerson DA, Tobe VO and Taylor SL (1997). PolyPhread: automating the detection and genotyping of single nucleotide substitutions using fluorescence-based resequencing. Nucleic Acids Res. 25: 2745-2751.

O’Rourke KI, Besser TE, Miller MW, Cline TF, et al. (1999). PrP genotypes of captive and free-ranging Rocky Mountain elk (Cervus elaphus nelsoni) with chronic wasting disease. J. Gen. Virol. 80 (Pt 10): 2765-2769.

O’Rourke KI, Spraker TR, Hamburg LK, Besser TE, et al. (2004). Polymorphisms in the prion precursor functional gene but not the pseudogene are associated with susceptibility to chronic wasting disease in white-tailed deer. J. Gen. Virol. 85: 1339-1346.

Pacheco ACL, Oliveira SMP, Gouveia JJS, Diniz MC, et al. (2007). Analysis of prion protein gene (PRNP) polymorphisms in healthy Morada Nova sheep reveals the presence of genotypes susceptible to scrapie. Cien. Anim. 17: 27-36.

Prusiner SB and Hsiao KK (1994). Human prion diseases. Ann. Neurol. 35: 385-395.

Sotomaior CS, Sotomaior VS, Madeira HM and Thomaz-Soccol V (2008). Prion protein gene polymorphisms in sheep in the State of Paraná, Brazil. Anim. Genet. 39: 659-661.

Vaccari G, Conte M, Morelli L, Di GG, et al. (2004). Primer extension assay for prion protein genotype determination in sheep. Mol. Cell Probes 18: 33-37.

Vaccari G, Panagiotidis CH, Acin C, Peletto S, et al. (2009). State-of-the-art review of goat TSE in the European Union, with special emphasis on PRNP genetics and epidemiology. Vet. Res. 40: 48. 